\title{
Value of in vivo electrophysiological measurements to evaluate canine small bowel autotransplants
}

\author{
M A C Meijssen, E Heineman, R W F de Bruin, H J Veeze, J Bijman, H R de Jonge, \\ F J W ten Kate, R L Marquet, J C Molenaar
}

\begin{abstract}
This study aimed to develop a non-invasive method for in vivo measurement of the transepithelial potential difference in the canine small bowel and to evaluate this parameter in small bowel autotransplants. In group 0 (control group, $n=4$ ), two intestinal loops were created without disturbing their vascular, neural, and lymphatic supplies. In group I (successful autotransplants, $\mathrm{n}=11$ ), two heterotopic small bowel loops were constructed. Long term functional sequelae of vascular, neural, and lymphatic division were studied. Group II $(n=6)$ consisted of dogs with unsuccessful autotransplants suffering thrombosis of the vascular anastomosis, which resulted in ischaemic small bowel autografts. In group I, values of spontaneous transepithelial potential difference, an index of base line active electrolyte transport, were significantly lower compared with group $0(p<0.05)$, probably as a result of denervation of the autotransplants. Both theophylline and glucose stimulated potential difference responses, measuring cyclic adenosine monophosphate mediated chloride secretion and sodium coupled glucose absorption respectively, showed negative luminal values in group I at all time points after transplantation. These transepithelial potential difference responses diminished progressively with time. From day 21 onwards both theophylline and glucose stimulated potential difference responses were significantly less than the corresponding responses at day seven $(p<0.05)$. Morphometric analysis showed that the reduction of transepithelial potential difference responses preceded degenerative mucosal changes in the heterotopic small bowel autografts. In group II, potential difference responses to theophylline and glucose showed positive luminal values ( $\mathbf{p}<0.01 v$ group $\mathrm{I}$ ), probably as a result of passive potassium effusion from necrotic enterocytes.
\end{abstract}

In small bowel transplantation, monitoring of the small bowel allograft for early recognition and treatment of rejection is mandatory. Because the value of functional tests to diagnose rejection continues to be debatable, ${ }^{1-13}$ rejection is currently evaluated by histological investigation only. ${ }^{1+16}$ Recent studies, however, have shown several shortcomings in histological monitoring. ${ }^{17-19}$ Mucosal biopsy specimens provide too little diagnostic information, while full thickness specimens produce a risk of perforation of the graft. ${ }^{17}$ In addition, a series of consecutive biopsy specimens is necessary for the evaluation of rejection, because of the patchy character of morphological changes. ${ }^{18}$

To gain more diagnostic value from histological monitoring, Kirkman and Madara investigated the effect of rejection on the electrophysiological function of small bowel grafts in a rat model by in vitro techniques. ${ }^{2021}$ The measurement of transepithelial potential differences (PD) of the small bowel is based on active electrolyte transport by sodium-potassiumadenosine triphosphatase localised at the basolateral membrane of the enterocyte. ${ }^{22}$ It was found that changes in the mucosal structure associated with rejection do correlate with a decreased spontaneous transpithelial PD. ${ }^{20}$ Furthermore, reduced responses to both sodium coupled glucose absorption, which is an index of villus function, ${ }^{23}$ and theophylline stimulated chloride secretion, an index, at least in part, of crypt cell function, ${ }^{24}$ were parallelled by structural abnormalities indicative of small bowel rejection. ${ }^{21}$ Recently Lee et al reported in vivo transepithelial PD as a marker of rejection in a rat small bowel transplant model..$^{25}$ They found that changes in transepithelial PD often occurred before histological changes. Because of the invasive nature of their method, however, they did not recommend it as a practical clinical tool..$^{25}$

The aim of our study was to develop a noninvasive method for in vivo measurement of transepithelial PD in the canine small bowel and to evaluate this parameter in small bowel autotransplants. This model was chosen to study the long term consequences of vascular, neural, and lymphatic interruption of the small bowel graft without the effects of rejection and immunosuppression. The electrophysiological parameters of the grafts were compared with the accompanying morphological characteristics.

\section{Methods}

\section{ANIMALS AND OPERATIVE TECHNIQUE}

Twenty one healthy adult Beagle dogs weighing 12 to $20 \mathrm{~kg}$ were used. The dogs were given neomycin $(2 \times 500 \mathrm{mg}$ orally for two days) and heparin ( $2 \times 500$ IU subcutaneously for two days) and food was withheld for 36 hours before surgery. Under general anaesthesia with endotracheal intubation and mechanical ventilation, a laparotomy was performed through a midline incision. A loop of distal ileum (length $50-65 \mathrm{~cm}$ ) from the proximal ileum to $5 \mathrm{~cm}$ proximal of the ileocecal valve was isolated on a vascular pedicle provided by a branch of the mesenteric artery and vein. This loop was removed and perfused with heparinised saline (5 IU heparin $/ \mathrm{ml} 0.9 \%$ saline) at $20^{\circ} \mathrm{C}$ until the venous effluent became 


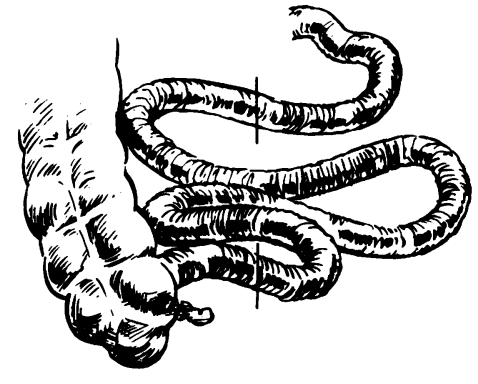

A

Figure 1: Model of canine small bowel transplantation. (A) Distal ileum and proximal colon before transplantation, note the levels of resection. $(B)$ Blind ended ileostomy and isoperistaltic Roux-Y loop in continuity with the distal ileum after transplantation.

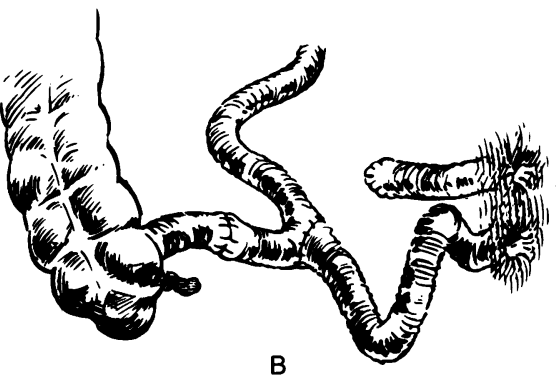

clear and the graft white. The right external iliac artery and vein were dissected. The graft was revascularised by anastomosis (with Prolene 7-0) of the mesenteric vessels to the iliac vessels in an end to side fashion. The graft was divided into two parts: a blind ending ileostomy (length 15$25 \mathrm{~cm}$ ) and an isoperistaltic Roux-Y loop in continuity with the distal ileum approximately $10 \mathrm{~cm}$ from the ileocaecal valve (length $25-35 \mathrm{~cm}$ ) (Fig 1). The blind ended loop was created for PD measurements, whereas the Roux-Y loop was constructed for future experiments, in which this heterotopic intestinal loop will be placed in an orthotopic position to compare it with orthotopic small bowel allografts. In this experiment both loops were used for obtaining histological specimens. Both small bowel loops were brought to the exterior as cutaneous ileostomies on the right side of the abdomen for monitoring purposes. Finally, continuity of the residual small bowel was restored (with Vicryl 4-0) by a single layer end to end anastomosis. Animals were treated with $5 \mathrm{ml}$ depomycin subcutaneously on the day of operation and $2.5 \mathrm{ml}$ depomycin and $2 \times 500$ IU heparin subcutaneously for five days thereafter. The dogs were supported with parenteral fluids $(0.9 \%$ saline and $5 \%$ glucose subcutaneously) until they were eating and drinking normally. All dogs were maintained on standard kennel rations (Canex, Hope Farms) and water was freely available.

\section{EXPERIMENTAL GROUPS}

The animals were divided into three groups:

Group $0(n=4)$ was the control group. In all these dogs a blind and an open ileostomy were constructed without creating the vascular pedicle and consequently without disturbing the vascular, neural, and lymphatic supply. These small bowel loops, which were not challenged by an ischaemic episode during operation and had an intact neural and lymphatic system, gave us the opportunity to study small bowel characteristics under normal physiological conditions.

Group I $(n=11)$ consisted of dogs who had undergone successful autotransplants. All these dogs received a blind and an open ileostomy as described. Cold ischaemic time averaged $36 \cdot 1$ minutes (range 30-43 minutes). In this group it was possible to study long term functional sequelae of autotransplanted small bowel without the influence of transplant rejection and immunosuppression.

Group II $(n=6)$ consisted of dogs who had undergone unsuccessful autotransplants. Autotransplantations were performed as in group I, but turned out to be technical failures as a result of thromobosis at the vascular anastomosis. Operative cold ischaemia averaged 37.3 minutes (range 33-43 minutes in this group). Before killing these dogs, electrophysiological parameters of ischaemic grafts were obtained two days $(n=2)$ and three days $(n=2)$ after operation.

\section{ELECTROPHYSIOLOGICAL MEASUREMENTS}

The blind ileostomy was used for electrophysiological tests. We developed a triple lumen double balloon catheter to isolate a $2.5 \mathrm{~cm}$ segment of the blind ileostomy (Fig 2). In this segment, a continuous flow of a test solution could be maintained at a constant rate of $10 \mathrm{ml} /$ minute by a peristaltic roller pump (Gilson, minipuls 3 ). One lumen of the triple lumen catheter introduced the test solution and a second served as an outflow channel. The third lumen contained a salt bridge (3\% agar in $0.9 \%$ saline) connected to

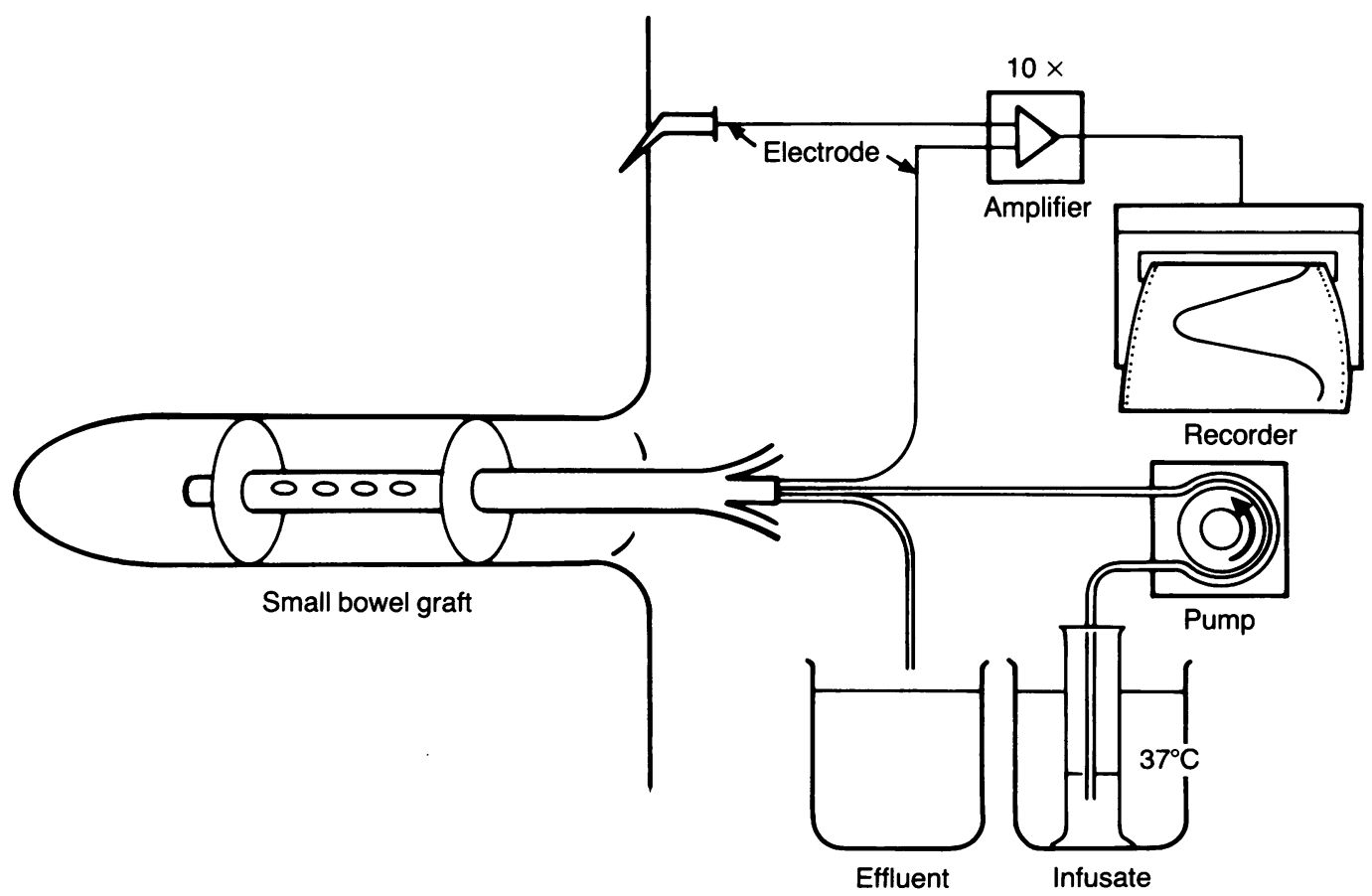


an $\mathrm{Ag} / \mathrm{AgCl}_{2}$ electrode $(0.5 \mathrm{~mm}$ in diameter, $7 \mathrm{~mm}$ in length). A sterile Teflon needle filled with $0.9 \%$ saline inserted in the right lower leg of the dog was connected to an $\mathrm{Ag} / \mathrm{AgCl}_{2}$ reference electrode $(0.5 \mathrm{~mm}$ in diameter, $7 \mathrm{~mm}$ in length). The transepithelial potential of the isolated ileal segment was measured in reference to the latter electrode. Both electrodes were connected to an amplifier. The transepithelial PD was visualised on a paper recorder (Kratos analytical recorder). To avoid electrophysiological disturbances, all dogs received $5 \mathrm{mg}$ droperidol intramuscularly before the measurements. The dogs tolerated handling of their ileostomies very well. Measurements of transepithelial PD were performed between 12 and 44 days after operation in group 0 , on days $3,7,10,14,21,42$, and 70 in group $I$, and on day 2 or 3 in group II.

\section{TEST SOLUTIONS}

During the electrophysiological measurements, three test solutions were used: $0.9 \%$ saline $(275$ $\left.\mathrm{mOsm} / \mathrm{kg} \mathrm{H}_{2} \mathrm{O}\right), 10 \mathrm{mmol} / 1$ theophylline in $0.9 \%$ saline $\left(285 \mathrm{mOsm} / \mathrm{kg} \mathrm{H} \mathrm{H}_{2} \mathrm{O}\right)$, and $40 \mathrm{mmol} / \mathrm{l}$ glucose in $0.9 \%$ saline $\left(312 \mathrm{mOsm} / \mathrm{kg} \mathrm{H}_{2} \mathrm{O}\right)$. The test solutions were instilled in the ileal segment at a temperature of $37^{\circ} \mathrm{C}$ and at a constant rate of 10 $\mathrm{ml} /$ minute. Spontaneous transepithelial PD, measuring base line active ion transport, was recorded by perfusing the ileal segment of the blind ileostomy with $0.9 \%$ saline over 30 minutes. After this equilibration period the ileal segment was challenged with $10 \mathrm{mmol} / \mathrm{l}$ theophylline in $0.9 \%$ saline for 30 minutes. Stimulated chloride secretion was assessed by measuring the peak PD response after the addition of theophylline. Thereafter, $0.9 \%$ saline was again instilled in the same bowel loop for 15 minutes, after which it was perfused with 40 $\mathrm{mmol} / \mathrm{l}$ glucose in $0.9 \%$ saline for 15 minutes. Sodium dependent active glucose absorption was assessed by measuring the peak PD response after exposure of the ileal segment to glucose. The above mentioned electrophysiological

TABLE I Base line transeithelial potential difference (base line $P D)$, theophylline stimulated $P D$ resonse $(P D$ theophylline), and glucose stimulated $P D$ response $(P D$ glucose). (Values, mean (SEM))

\begin{tabular}{|c|c|c|c|}
\hline & $\begin{array}{l}\text { Base line PD } \\
(m V)\end{array}$ & $\begin{array}{l}\text { PD-theophylline } \\
(m V)\end{array}$ & $\begin{array}{l}\text { PD-glucose } \\
(m V)\end{array}$ \\
\hline \multicolumn{4}{|c|}{ Group 0 (control): } \\
\hline Day 21 & $\begin{array}{l}i \cdot 33(0.42) \\
n=4\end{array}$ & $\begin{array}{c}-4 \cdot 13(0 \cdot 45) \\
n=4\end{array}$ & $\underset{n=4}{-5 \cdot 68(0.81)}$ \\
\hline \multicolumn{4}{|c|}{ Group I (ileal autotransplants): } \\
\hline Day 3 & $\begin{array}{l}-1.41(0.87) \\
n=8\end{array}$ & $\begin{array}{c}-3 \cdot 23(0 \cdot 50) \\
n=8\end{array}$ & $\begin{array}{c}-2 \cdot 20(0 \cdot 38)^{\star} \\
\mathrm{n}=8\end{array}$ \\
\hline Day 7 & $\begin{array}{c}-2 \cdot 79(0 \cdot 96) \\
n=7\end{array}$ & $\begin{array}{c}-3 \cdot 56(0 \cdot 50) \\
n=7\end{array}$ & $\begin{array}{c}-4 \cdot 02(0.53) \\
n=6\end{array}$ \\
\hline Day 10 & $\begin{array}{c}-1.61(0.95) \\
n=8\end{array}$ & $\begin{array}{c}-2 \cdot 47(0.31) \\
\mathrm{n}=8\end{array}$ & $\begin{array}{c}-3 \cdot 16(0 \cdot 46) \\
n=7\end{array}$ \\
\hline Day 14 & $\begin{array}{l}-0 \cdot 67(0 \cdot 20) \\
\mathrm{n}=7\end{array}$ & $\begin{array}{c}-2 \cdot 41(0 \cdot 33) \\
n=7\end{array}$ & $\begin{array}{c}-3 \cdot 1(0 \cdot 56) \\
n=6\end{array}$ \\
\hline Day 21 & $\begin{array}{c}-1.83(1.03) \dagger \\
\mathrm{n}=7\end{array}$ & $\begin{array}{c}-2 \cdot 17 \\
\mathrm{n}=7\end{array}(0 \cdot 25) \dagger \ddagger$ & $\begin{array}{c}-2 \cdot 69(0 \cdot 35) \dagger \ddagger \\
\mathrm{n}=7\end{array}$ \\
\hline Day 42 & $\begin{array}{c}-1 \cdot 24(0.98) \\
n=7\end{array}$ & $-1.61(0.41)^{\star}$ & $\begin{array}{c}-1.45 \\
n=7\end{array}$ \\
\hline Day 70 & $\begin{array}{l}0.39(0.89)^{\star} \\
\mathrm{n}=8\end{array}$ & $\begin{array}{c}-1.98(0.25)^{\star} \\
n=8\end{array}$ & $\begin{array}{c}-2.06(0.41)^{\star} \\
n=8\end{array}$ \\
\hline \multicolumn{4}{|c|}{ Group II (unsuccessful autotransplants): } \\
\hline Days $2 / 3$ & $\begin{array}{l}1 \cdot 25(1 \cdot 11) \\
n=4\end{array}$ & $\begin{array}{l}0.83(0.35) \\
n=4\end{array}$ & $\begin{array}{l}0.46(0.31) \oint \\
n=4\end{array}$ \\
\hline
\end{tabular}

${ }^{\star} \mathrm{p}<0.05$ compared with corresponding PD response at day 7. $t \mathrm{p}<0.05$ compared with group 0 on day 21 . $\neq \mathrm{p}<0.01$ compared with group 0 on day 21 . $\S \mathrm{p}<0.01$ compared with group I on day 3 . responses to theophylline and glucose are widely used indices of these specific transport processes. ${ }^{22}{ }^{26}$ At the end of the electrophysiological test, the small bowel loop was again perfused with $0.9 \%$ saline for 15 minutes.

\section{MORPHOLOGY}

On the day of electrophysiological measurements, biopsy specimens were obtained by biopsy forceps from both the blind and the open ileostomy at approximately 5 to $7 \mathrm{~cm}$ from the cutaneous stoma. The specimens were fixed in $10 \%$ buffered formalin, dehydrated, and embedded in paraffin. Haematoxylin azophloxin stained sections $(4-5 \mu \mathrm{m})$ were prepared and subsequently examined by light microscopy. Morphometric analysis of villus height and crypt depth was performed on each histological section as described previously. ${ }^{27}$ Necropsies were performed on the dogs in the control group (group 0) 100 days after operation and on group II dogs on the day they were killed, between two and six days after transplantation. The group I dogs were not sacrified and are currently used for long term follow up.

\section{STATISTICAL METHODS}

All data are expressed as mean (SEM). Comparisons of electrophysiological parameters between the same animals at different time points were performed using the paired Student's $t$ test. Differences in electrophysiological parameters between the various experimental groups were analysed using Student's $t$ test for two means. Statistical analysis of mucosal morphometry between the same animals at different time points was performed using the Wilcoxon rank sum test and for comparisons between group 0 and I the Mann-Whitney U test was used. For all tests $\mathrm{p}<0.05$ was considered significant.

\section{Results}

\section{POSTOPERATIVE COURSE}

All dogs from group 0 and 10 dogs from group I survived an observation period of 10 weeks. One dog from group I died eight days after operation as a result of a wound abscess. Six dogs in group II had to be killed between two and six days after operation because of a deteriorating condition. At necropsy thrombus formation at the arterial and venous anastomosis, causing haemorrhagic ischaemic necrosis of the graft, was found. Although these dogs could be regarded as technical failures, electrophysiological parameters obtained in four proved a valuable source of information on ischaemic small bowel grafts.

\section{GROUP 0: CONTROL GROUP}

In this group, 10 series of electrophysiological measurements were obtained from four dogs between 12 and 44 days after operation. During this test period data on transepithelial PD were not collected systematically. As a result only electrophysiological data obtained on day 21 could be used for statistical analysis (Table I). 
Figure 3: (A) Normal histological appearance of small bowel architecture of blind ending ileostomy in group 0 at postoperative day 69 (haematoxylin and azophloxin $(H$ and $A$ ) stain, original magnification $\times 100)$. $(B)$ Histological appearance of ileal autotransplant in group I obtained on postoperative day 3. Reduced height of villi, dilated lymph vessels, and oedema are present ( $H$ and $A$ stain, original magnification $\times 100$ ). (C) Histological appearance of ileal graft in group I on postoperative day 51 . Reduction in villus height and crypt depth and fibrosis of lamina propria are present $(H$ and $A$ stain, original magnification $\times 100$ ). (D) Histological appearance of small bowel graft in group II showing ischaemic

necrosis at postoperative day 3 ( $H$ and $A$ stain, original magnification $\times 100$ ).
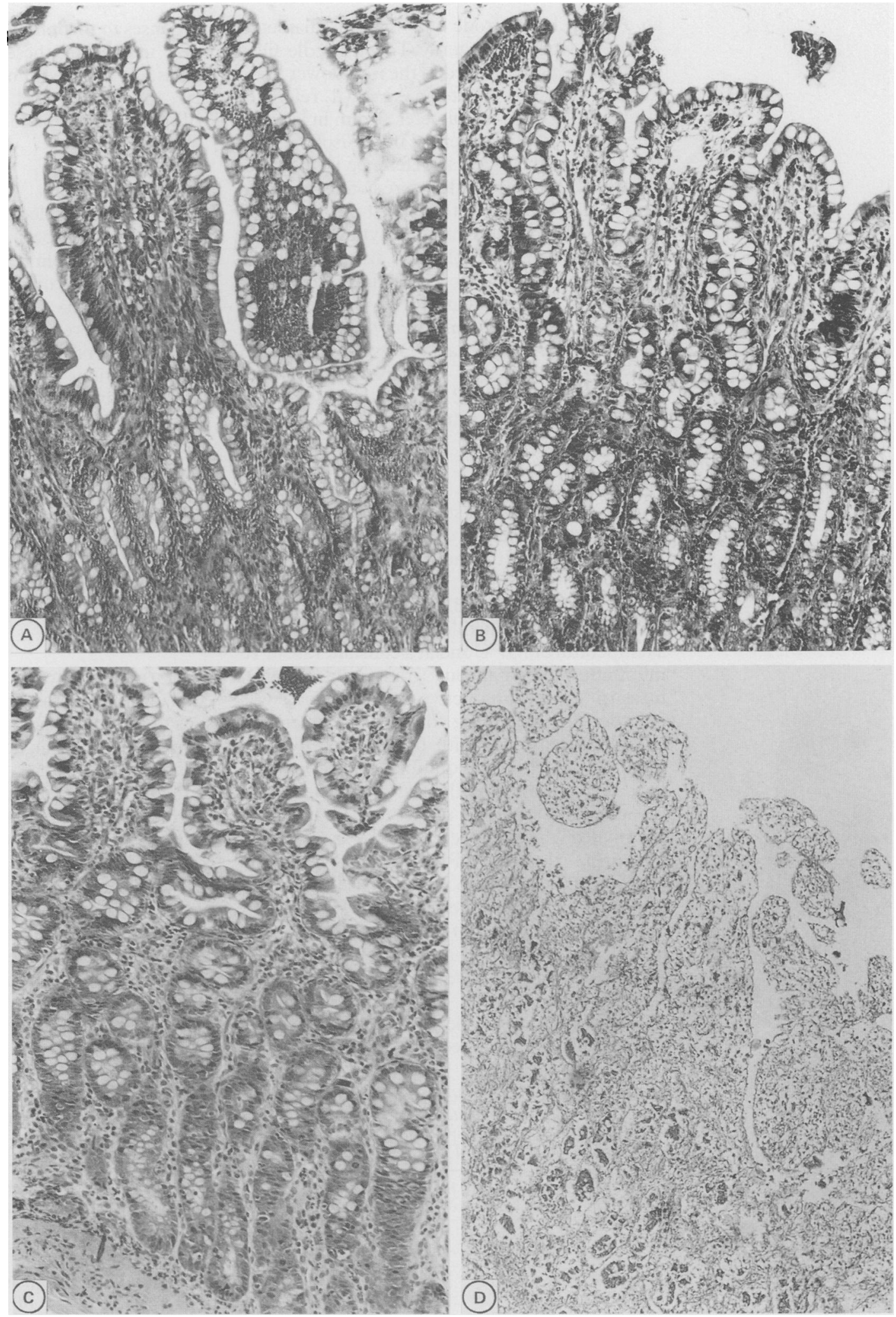

Perfusion of the ileal segment with $0.9 \%$ saline provided a positive luminal base line transepithelial PD at all time points after operation. Addition of $10 \mathrm{mmol} / \mathrm{l}$ theophylline in $0.9 \%$ saline caused a negative luminal peak $P D$ response in reference to the base line PD. Instillation of $40 \mathrm{mmol} / \mathrm{l}$ glucose in $0.9 \%$ saline also showed a negative peak PD response in reference to the spontaneous transephithelial PD. The theophylline and glucose evoked potential increments disappeared within several

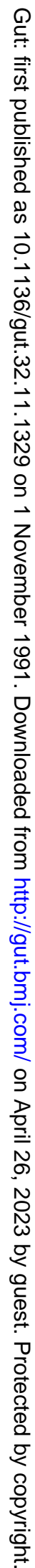

minutes after perfusing the ileal segment with $0.9 \%$ saline.

Biopsy specimens taken simultaneously from both small bowel loops were histologically identical and showed structurally normal small bowel architecture between 12 and 44 days after operation (Fig 3A). Necropsy at day 100 after operation showed a considerable villus shortening of the ileal grafts (Table II). Because of the limited number of animals, however, the difference from day 0 was not statistically significant 
TABLE II Morphometric analysis of villus height and crypt depth in groups 0 and I. (Values mean $(S E M)$ )

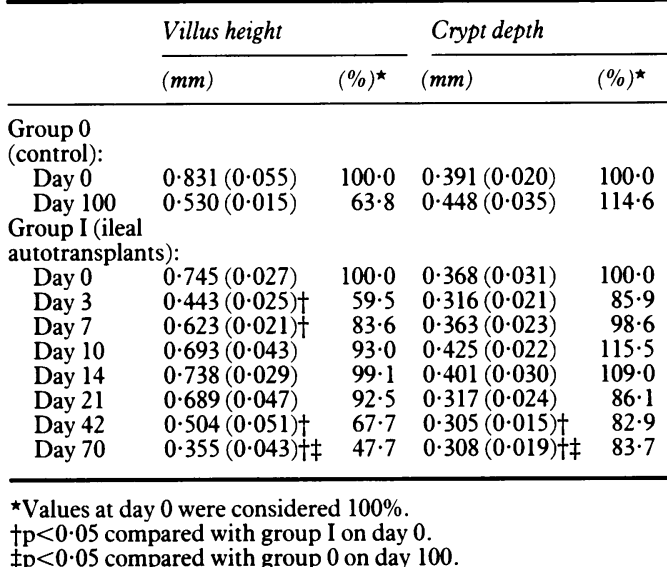

$(p=0.07)$. The deeper layer of the lamina propria of the ileal grafts showed a substantial amount of fibroblasts and fibrosis. At day 100 the crypt depth was not different to that at day 0 (Table II).

GROUP I: SUCCESSFUL AUTOTRANSPLANT GROUP The results are shown in Tables I and II and Figure 4. In contrast to the control group, perfusion of the ileal graft with saline caused a negative luminal base line transepithelial PD in this group at all time points except day 70 . Throughout the test period these base line PD measurements showed a considerable range. However, the base line PD on day 70 differed significantly from the corresponding response on day seven $(p<0 \cdot 05)$. Analysis of the base line PD responses in groups 0 and $I$ showed that the PD response differed significantly in group I from that in group 0 on day $21(\mathrm{p}<0.05)$.

Stimulated active chloride secretion after exposure to $10 \mathrm{mmol} / \mathrm{l}$ theophylline resulted in negative luminal peak PD responses at all time points after transplantation, but from day seven onwards these responses reduced progressively during the remainder of the test period. From day 21 onwards the peak $P D$ responses to theophylline were significantly lower than the corresponding response on day seven $(\mathrm{p}<0.05)$. Compared with group 0 , the PD response to theophylline was significantly reduced in group I on day $21(\mathrm{p}<0.01)$. response (PD-glucose) in group I. Results are expressed in $m V$ (mean $(S E M))$.

Figure 4: Base line potential difference $(P D)$, theophylline stimulated $P D$ response (PD-theophylline)

QD PD baseline $\mathrm{NIN}$ PD-theophylline $\%$ PD-glucose

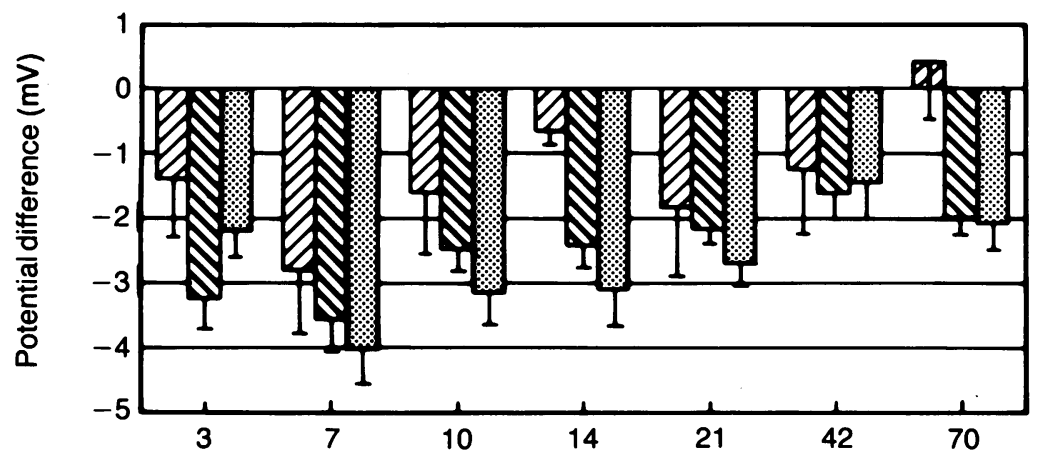

Time after transplant (days)
Exposure of the ileal graft to $40 \mathrm{mmol} / \mathrm{l}$ glucose resulted in negative luminal peak PD responses at all time points. On day three, however, the PD response was significantly reduced compared with the response on day seven $(p<0.05)$. From day seven onwards the PD responses to glucose progressively decreased and after day 21 the response to glucose was significantly less than the PD response on day seven $(p<0.05)$. Compared with the control group, the PD response to glucose was significantly reduced in group I on day $21(\mathrm{p}<0.01)$.

Histological and morphometric evaluation of the biopsy specimens of the small bowel grafts showed a significantly reduced villus height with dilated lymph vessels on day three after transplantation $(\mathrm{p}<0.05 v$ day 0$)$, whereas the crypt depth was not altered (Fig 3B and Table II). After day three the height of the villi gradually increased to reach a normal morphological pattern on day 10. From day 42 onwards progressive changes in mucosal structure were found: a significant reduction in both villus height and crypt depth $(\mathrm{p}<0.05 v$ day 0$)$ and substantial numbers of fibroblasts and fibrosis in the deeper layer of the lamina propria (Fig 3C). In some instances a polymorphonuclear cell infiltrate of the mucosa and cryptitis were found. The reduction of villus height in group I on day 70 was more pronounced than the reduction in group 0 on day $100(p<0.05)$. On day 70 the crypt depth in group I was also significantly smaller compared with the crypt depth in group 0 on day $100(\mathrm{p}<0.05)$.

GROUP II: UNSUCCESSFUL AUTOTRANSPLANTS

Results are shown in Table 1. Because of the deteriorating condition of the dogs in group II, electrophysiological parameters could only be obtained on day two in two dogs and on day three in two other dogs. The cutaneous stomas of the grafts had a brown and dry appearance and produced blood stained secretions on day two or three. The spontaneous transepithelial PD had a positive luminal value on day two or three. However, this PD response was not statistically different from the base line PD of group I. Peak PD responses to both theophylline and glucose stimulation showed positive values and were different compared with the corresponding responses in group I $(\mathrm{p}<0.01)$.

At necropsy histological examination showed changes comparable with haemorrhagic ischaemic necrosis of the grafts (Fig 3D).

\section{Discussion}

The results of our study show that in vivo recording of electrophysiological parameters of the canine small bowel is technically feasible. By using an autotransplant model long term electrophysiological and morphological consequences of vascular, neural, and lymphatic division could be studied. Furthermore, long term effects in non-functional small bowel loops were evaluated.

The intestinal mucosa can be divided into two complementary entities: the crypts, in which 
electrogenic chloride secretion occurs, ${ }^{24}$ and the villi, in which nutrient absorption, including sodium and glucose, takes place. ${ }^{23}$ The spontaneous transepithelial PD, an index of base line active transport, results from electrogenic sodium absorption and chloride secretion.

Saline perfusion of the control grafts, in which the vascular, neural, and lymphatic supplies were not disturbed, resulted in positive luminal base line PD responses at all time points after operation. Addition of a theophylline solution resulted in negative luminal PD responses with reference to the base line $\mathrm{PD}$. This is because of theophylline stimulated and cyclic adenosine monophosphate mediated chloride secretion by the crypt cells. ${ }^{22}$ It is based on a $\mathrm{Na}-\mathrm{K}-\mathrm{Cl}_{2}$ cotransporter in the basolateral membrane which leads, driven by $\mathrm{Na}$-K-adenosine triphosphate, to cellular accumulation of chloride that subsequently leaves the crypt cell through the apical membrane. Perfusion of the control grafts with glucose in saline caused negative luminal peak PD responses as well. This is a result of active glucose absorption by the villus cells with a cotransport of sodium that leads to an increase in net transmural sodium absorption. ${ }^{26}$ In the control group the results of base line PD and stimulated PD responses obtained between 12 and 44 days after operation did not vary very much. Unfortunately, data collection was not complete in group 0 . As a consequence, only data obtained in all four dogs at day 21 could be used for statistical analysis. Because the biopsy specimens of the control grafts showed normal small bowel architecture between days 12 and 44 after operation, the electrophysiological responses obtained at day 21 may well reflect a physiological situation.

In contrast to the control group, the base line transepithelial PD in group I showed negative luminal values at all time points except day 70 . This difference is probably the result of an enhanced secretory activity of the crypts caused by denervation, since the crypts are under much greater autonomic neurological control than the villi. ${ }^{28}$ Furthermore, nerve stimulation inhibits electrogenic chloride secretion and stimulates fluid absorption. ${ }^{30}$ Thus, the observed negative luminal base line PD may have been caused by net chloride secretion by crypts no longer controlled by the autonomic nervous system. Our findings agree with those of Watson et al, who found chloride secretion in denervated ThiryVella loops, whereas innervated control ThiryVella loops absorbed chloride. ${ }^{31}$ This effect may have considerable implications for clinical small bowel transplantation. Our findings show that even without the deleterious influence of rejection and complications of immunosuppressive drugs, denervation in intestinal autotransplants results in functionally altered small bowel grafts. Unless reinnervation occurs, an abnormal digestive and absorptive intestinal (auto-)transplant can be expected. ${ }^{31} 32$

In group I, the glucose stimulated response, assessing the sodium coupled glucose transport, was substantially reduced on day three compared with day seven. This decreased absorptive response correlated well with histology, which showed a significantly reduced villus height on day three compared with day seven. This is probably a result of the short period of ischaemia during transplantation. It is known that the intestinal mucosa is highly sensitive to ischaemic injury. ${ }^{33}$ Reperfusion injury generated by oxygen derived free radicals also damages intestinal mucosa. ${ }^{34}$ Nevertheless, the small bowel has an enormous regenerative potential after a short period of ischaemia. ${ }^{33}$ Regeneration starts in the crypts and regenerated enterocytes gradually migrate from the crypts to the villus tips. This could explain why the glucose stimulated response, which is a villus function, was still reduced on day three, whereas at the same time the regenerated crypt cells caused a normal PD response after theophylline stimulation.

In group I, both theophylline and glucose stimulated PD responses showed negative luminal values, but these responses decreased progressively with time: from day 21 onwards both theophylline and glucose responses were significantly less than the corresponding responses on day seven. Morphometric changes followed electrophysiological ones, but after some delay. From day 42 onwards a significant reduction in both villus height and crypt depth and progressive fibrosis of the deeper layer of the lamina propria were found. These changes, indicative of mucosal atrophy, are known to occur when the small bowel is deprived of intraluminal nutrition. ${ }^{35-37}$ Furthermore, our results are supported by the finding that blind loops are characterised by impaired active ion transport processes and an increase in epithelial and subepithelial resistance as reported by Schulzke et al..$^{38}$ After day 42 we found a polymorphonuclear cell infiltrate of the mucosa and cryptitis in some dogs, suggesting a bacterial infection. This could be explained by bacterial overgrowth in the small bowel loops with a damaging effect on the mucosa.

It is interesting to note that the reductions in theophylline and glucose stimulated PD responses, which are caused by stimulated active ion transport processes, precede the degenerative morphological changes in the small bowel mucosa. The importance, however, of the base line PD responses, measuring the base line active transport processes, remains uncertain. Only on day 70 did the base line PD value show a significant difference from that on day seven. This is probably because of the considerable range in base line PD responses, which suggests a substantial physiological variation in base line ion transport by enterocytes.

Our findings show that the mucosal atrophy in the autotransplants is more advanced than in the control group. Comparison between groups 0 and I showed significantly smaller PD responses to theophylline and glucose in group I on day 21 . Morphometric analysis in group 0 showed no mucosal alterations before day 44 , whereas reduction of both villus height and crypt depth was evident in the autotransplanted small bowel loops of group I from day 42 onwards. In addition, comparison between groups 0 and I showed sigificantly smaller villi and crypts in group I on day 70 compared with group 0 on day 100. This discrepancy cannot be explained by lymphatic disruption as lymphatic reconnection 
to small bowel autotransplants occurs within a few weeks of surgery. ${ }^{39}$ Thus, the degenerative changes in the small bowel mucosa may be accelerated by denervation of the graft.

Although the base line PD responses in group II (which suffered acute ischaemia as a result of thrombosis at the vascular anastomosis) showed positive luminal values, the difference with group I was not significant on day three. The theophylline and glucose stimulated PD responses in group II were, however, completely different from those of group I. Because an active electrolyte transport mechanism cannot be expected in ischaemic necrotic cells, these electrophysiological results may reflect passive ion diffusion processes, probably potassium effusion from necrotic cells resulting in a positive luminal PD response. It has been suggested that focal endothelial cell injury of the microvasculature is an important factor in acute rejection of the small bowel transplant. ${ }^{21}$ If the rejection episode is not reversed, swelling of the endothelial cells will result in persistent ischaemia which will eventually damage the transplant. Thus, although we have no direct evidence, the electrophysiological parameters of group II may reflect those of an end stage rejected small bowel graft.

In summary, this study showed that in vivo evaluation of electrophysiological parameters of canine small bowel is feasible and provides a useful, practical tool in the functional assessment of small bowel autotransplants. We found that denervation in intestinal autotransplants causes functional changes in small bowel mucosa. Unless reinnervation occurs, the transplant will have abnormal digestive and absorptive capabilities. Our findings show that reductions in transepithelial PD responses precede degenerative mucosal alterations in the autotransplanted small bowel. Since in vitro studies have clearly shown the correlation between electrophysiological and structural changes in intestinal allograft rejection, our in vivo method could be used for indirect monitoring of functional and structural changes of the small bowel allograft.

This work was supported by a grant of the Sophia Foundation for Medical Research, project No 80.

Previously published in part in the abstract book of the International congress on small bowel transplantation, St Bartholomew's Hospital, London, England, 11-13 October 1989.

1 Schraut WH. Current status of small-bowel transplantation Gastroenterology 1988; 94: 525-38.

2 Billiar TR, Garberoglio C, Schraut WH. Maltose absorption as an indicator of small-intestinal allograft rejection. F Surg Res 1984; 37: 75-82.

3 Nordgren S, Cohen Z, Mackenzie R, Finkelstein D, Greenberg GR, Langer B. Functional monitors of rejection in small intestinal transplants. Am $\mathcal{F}$ Surg 1984; 147: 152-8.

4 Reznick RK, Craddock GN, Langer B, Gilas T, Cullen JB. Structure and function of small bowel allografts in the dog: Structure and function of small bowel allografts in the dog:
immunosuppression with Cyclosporine A. Can $\mathcal{F}$ Surg 1982;

5 Maeda K, Oki K, Nakamura K, Schwartz MZ. Small intestine transplantation: a logical solution for short bowel syndrome? $\mathcal{f}$ Pediatr Surg 1988; 23: 10-5.

6 Teitelbaum DH, Dunaway DJ, Sonnino RE, Stellin G, Berend ME, Harmel RP Jr. Leakage of intraluminal low molecular weight polyethylene glycol as a marker of smal
bowel transplant rejection. F Pediatr Surg 1989; 24: 64-9.

7 Teitelbaum DH, O'Dorisio TM, Qualman SJ, Sonnino RE, Dunaway DJ, Harmel PR Jr. Alteration in gastrointestinal peptide tissue levels in rejecting small bowel transplants. peptide tissue levels in rejecting
$\mathcal{F}$ Pediatr Surg 1989; 24: 629-33.

8 Teitelbaum DH, Wise WE, Sonnino RE, et al. Monitoring of intestinal transplant rejection. Am F Surg 1989; 157: 318-22.

9 Holmes JT, Yeh SDJ, Winawer SJ, Kawano N, Fortner JG. Absorption studies in canine jejunal allografts. Ann Surg 1971; 174: 101-8.
10 Dennison AR, Collin J, Watkins RM, Millard PR, Morris PJ. Segmental small intestinal allografts in dogs. I. Morphological and functional indices of rejection. Transplantation $1987 ; 44: 474-8$.

11 Jarling J, Lorenz D, Attig D. Evaluation of intestinal tests after autologous small-intestinal transplantation in dogs. Eur after autologous small-intestinal tra
Surg Res 1988; 20 (suppl 1): 126-7.

12 Silverman R, Cohen Z, Levy G, Craig M, Cullen J, Langer B. Immune responses in small intestinal transplantation in the rat: correlation of histopathology and monocyte procoagulant activity. Surgery 1987; 102: 395-401.

13 Maeda K, Schwartz MZ, Bamberger MH, Daniller A. A possible serum marker for rejection after small intestine transplantation. Am F Surg 1987; 153: 68-74.

14 Rosemurgy AS, Schraut WH. Small bowel allografts. Sequence of histologic changes in acute and chronic Sequence of histologic changes in
rejection. Am $\mathcal{F}$ Surg 1986; 151: 470-5.

15 Lossing A, Nordgren S, Cohen Z, Cullen J, Craddock G Langer B. Histologic monitoring of rejection in small intestinal transplantation. Transplant Proc 1982; 14: 643-5.

16 Holmes JT, Klein MS, Winawer SJ, Fortner JG. Morphological studies of rejection in canine jejunal allografts Gastroenterology 1971; 61: 693-706.

17 Millard PR, Dennison A, Hughes DA, Collin J, Morris PJ. Morphology of intestinal allograft rejection and the inadequacy of mucosal biopsy in its recognition. $B r \mathcal{F} \operatorname{Exp}$ Pathol 1986; 67: 687-98.

18 Grant D, Sommerauer J, Mimeault R, et al. Treatment with continuous high-dose intravenous cyclosporine following clinical intestinal transplantation. Transplantation 1989; 48: 151-2.

19 Schmid T, Oberhuber G, Körözsi G, Klima G, Margreiter R. Histologic pattern of small bowel allograft rejection in the rat. Mucosal biopsies do not provide sufficient information. Gastroenterology 1989; 96: 1529-32.

20 Kirkman RL, Lear PA, Madara JL, Tilney NL. Smal intestine transplantation in the rat - Immunology and function. Surgery 1984; 96: 280-7.

21 Madara JL, Kirkman RL. Structural and functional evolution of jejunal allograft rejection in rats and the ameliorating effects of cyclosporine therapy. $\mathcal{F}$ Clin Invest 1985; 75: 50212 .

22 Donowitz M, Welsh MJ. Regulation of mammalian smal intestinal electrolyte secretion. In: Johnson LR, ed. intestinal electrolyte secretion. In: Johnson LR, ed.
Physiology of the gastrointestinal tract. 2nd ed. vol 2. New York: Raven Press, 1987: 1351-88.

23 Donowitz M, Madara JL. Effect of extracellular calcium depletion on epithelial structure and function in rabbi ileum: a model for selective crypt or villus epithelial cell damage and suggestion of secretion by villus epithelial cells Gastroenterology 1982; 83: 1231-43.

24 Welsh MJ, Smith PL, Frizzell RA. Crypts are the site of intestinal fluid and electrolyte secretion. Science $1982 ; 218$ : 1219-21.

25 Lee MD, Smith SD, Yunis EJ, Rowe MI. In vivo transmura potential difference: an early monitor of rejection in small potential difference: an early monitor of rejection in

26 Schultz SG. Ion-coupled transport across biological membranes. In: Audreoli TE, Hofmann JR, Fanestil DD, eds Physiology of membrane disorders. New York: Plenum, 1981 273-86.

27 Shiner M, Doniach I. Histopathologic studies in steatorrhea. Gastroenterology 1960; 38: 419-40.

28 Siövall H, Redfors S, Hallbäck DA, Eklund S, Jodal M, Lundgren $\mathrm{O}$. The effect of splanchnic nerve stimulation on blood flow distribution, villous tissue osmolality and fluid and electrolyte transport in the small intestine of the cat. Acta Physiol Scand 1983; 117: 359-65.

29 Jacobowitz D. Histochemical studies of the autonomic innervation of the gut. $\mathcal{F}$ Pharmacol $E x p$ Ther $1965 ; 149$ : 358-64.

30 Brunsson I, Eklund S, Jodal M, Lundgren O, Sjövall H. The effect of vasodilatation and sympathetic nerve activation on net water absorption in the cat's small intestine. Acta Physio Scand 1979; 106: 61-8.

31 Watson AJM, Lear PA, Montgomery A, et al. Water, electrolyte, glucose, and glycine absorption in rat small intestina transplants. Gastroenterology 1988; 94: 863-9.

32 Raju S, Fujiwara H, Grogan JB, Achord JL. Long-term nutritional function of orthotopic small bowel autotransplants. F Surg Res 1989; 46: 142-6.

33 Robinson JWL, Mirkovitch V, Winistörfer B, Saegesser F. Response of the intestinal mucosa to ischaemia. Gut 1981; 22: $512-27$.

$34 \mathrm{McCord}$ JM. Oxygen-derived free radicals in postischemic tissue injury. NEngl f Med 1985; 312: 159-63.

35 Riecken EO, Stallmach A, Zeitz M, Schulzke JD, Menge H, Gregor M. Growth and transformation of the small intestinal mucosa - importance of connective tissue, gut associated lymphoid tissue and gastrointestinal regulatory peptides. Gut 1989; 30: 1630-40.

36 Hosoda N, Nishi M, Nakagawa M, Hiramatsu Y, Hioki K, Yamamoto $M$. Structural and functional alterations in the gut of parenterally or enterally fed rats. F Surg Res 1989; 47 129-33.

37 Dworkin LD, Levine GM, Farber NJ, Spector MH. Small intestinal mass of the rat is partially determined by indirect effects of intraluminal nutrition. Gastroenterology 1976; 71 . 626-30.

38 Schulzke JD, Fromm M, Menge H, Riecken EO. Impaired intestinal sodium and chloride transport in the blind loop syndrome of the rat. Gastroenterology 1987; 92: 693-8.

39 Kocandrie V, Houttuin HE, Prohaska JV. Regeneration of the lymphatics after autotransplantation and homotransplantation of the entire small intestine. Surg Gynecol Obstet 1966; 122: 587-92. 